Erdinč Rakipovski $\bowtie$

Dragan Milčič

https://doi.org/10.21278/TOF.44307

ISSN 1333-1124

eISSN 1849-1391

\title{
VALIDATION TESTING OF AN INNOVATIVE BRAKING SYSTEM FOR FREIGHT WAGONS
}

\begin{abstract}
Summary
In this study, validation tests have been conducted on an innovative braking system for freight wagons. The paper presents the results of the tests, which are crucial for the approval of the braking system. Considering that the braking system is of great importance for the safety of rail transport and that it is exposed to high static and dynamic loads in external conditions, a series of tests were carried out to validate the braking system. The testing of the braking system was carried out on specialized test tracks in order to check if the technical requirements are met. The results from the validation tests of the innovative braking system are positive.
\end{abstract}

Key words: $\quad$ braking system, freight wagons, stand, testing

\section{Introduction}

Product development emphasizes the importance of bringing new products to the market to perpetuate the success of a particular business [1]. It also contributes to the growth of companies, affects profit and plays a key role in business planning. Studies have shown that product development is relatively inexpensive and low risk, but it can lead to significant competitive advantages in terms of cost savings, customer engagement and profits, and can only be achieved if the process of product creation is conducted in the right way [2]. In essence, the management of product development is not different from any other requirements as goals need to be set and then accomplished. For these reasons, research in product and process development is very important.

Rail transport plays a crucial part in a society, not only as it allows a large number of people to get to work every day, but also in terms of transport of goods. The development of rail transport in recent decades is aimed at increasing the speed and loading performance of railway vehicles. This directly affects the development of the brake technology. The braking system has an essential function in the reduction of speed and the braking of the rolling stock in the minimum possible time [2]. This shows that the braking system plays a vital role in the safety of railway vehicles.

Validation testing is the process of ensuring that the tested product satisfies the necessary criteria and the client's needs. In order to validate a braking system, several tests 
need to be done: static testing, dynamic testing, cyclic testing, climate chamber testing, slip testing, etc. This paper will analyse only the static and the slip testing.

The results obtained from the validation tests of the innovative braking system IBB 10 will indicate whether the braking system meets the UIC standard criteria. Also, the slip testing results of the innovative braking system IBB 10 will be compared with the slip testing results of the classic braking system.

\section{Classic braking system and innovative braking system}

The braking system is a part of the railway equipment that ensures a safe deceleration and stopping of the railway vehicle when necessary [3]. In terms of safety, it is more important that the vehicle should stop than continue moving, so it can be concluded that the braking system plays a key role in railway safety. Keeping in mind the importance of the braking equipment for the railway vehicles, all operators pay special attention to the development and maintenance of braking systems.

George Westinghouse realized the importance of the safety system of the braking system as early as 1869 and innovated the first braking system with a triple valve. In the same year, he founded Westinghouse Air Brake Company (WABCO). His air brake system was much safer, had faster reaction time and thus became a basis for a modern braking system [2]. Figure 1 represents a schematic diagram of an air brake system.

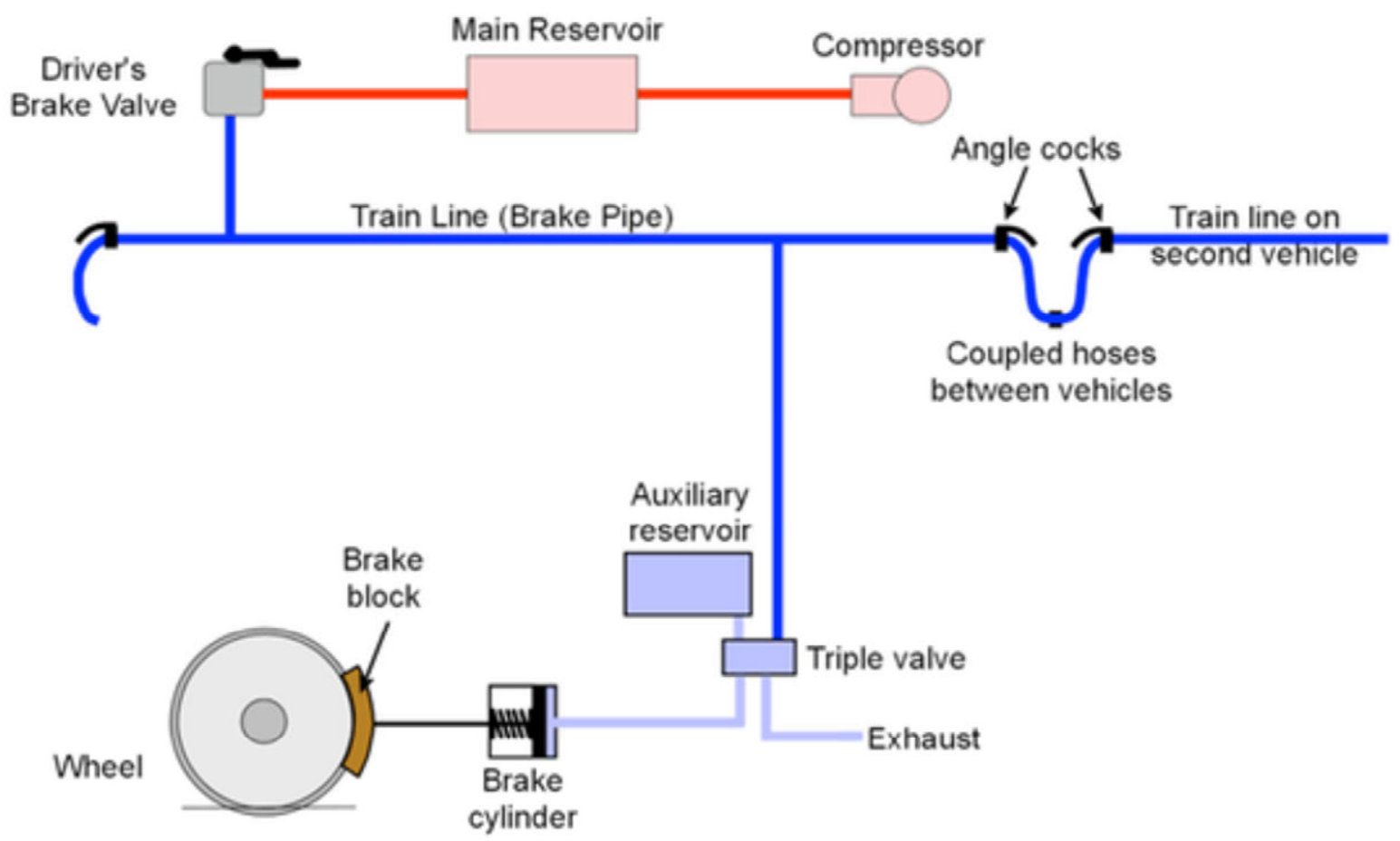

Fig. 1 Schematic diagram of an air brake system [4]

Air is drawn into a compressor and stored in a main reservoir at 7-10 bar. The compressed air from the main reservoir is distributed along the train through the main reservoir pipe. On each vehicle, the pipe is connected by a triple valve to an auxiliary reservoir that stores air for use on that vehicle's braking system. The flow of air between the auxiliary reservoir and the brake cylinders is controlled by the triple valve. The control of the triple valve is achieved by varying the pressure in a second pipe called the brake pipe, which is connected to a brake valve in the driver's compartment. Increasing the pressure in the brake pipe causes the brakes to release, while decreasing the pressure causes the brakes to apply. 
The triple valve is also called a three-way valve because of the three functions it performs:

1. Charging. When the wagon is stationed, there is no pressure in the brake pipe. First, it is necessary to charge the air brakes. This is achieved by increasing the pressure in the brake pipe from which the triple valve directs the pressure into the wagon auxiliary reservoir, where the pressure is held to be used later when the brakes are applied.

2. Applying. When it is necessary to apply the brakes, the driver sets the brake handle in such a way that air is removed from the brake pipe. This pressure drop is detected by the triple valve that re-directs the pressure from the auxiliary reservoir to the brake cylinder, after which the brakes are activated.

3. Releasing. Once the brakes are applied, the triple valve will detect an increase in the pressure in the brake pipe, which will release the brakes (the brake cylinder pressure is released into the atmosphere) and start to recharge the auxiliary reservoir.

George Westinghouse's triple valve improved (accelerated) the response time because it did not need to move all the air needed to activate the brakes. It only had to move enough air to carry a signal to the triple valve to activate or release the brakes. However, it took a while for the signal to move down the brake pipe.

After several years, George Westinghouse developed an additional safety feature of the braking system by introducing an emergency braking application. To achieve this, it was necessary to add a second reservoir, which allowed the application of more power to the brakes. This enabled the train to stop at a shorter distance, which increased safety.

\subsection{Classic braking system for freight wagons}

The classic(conventional) braking system for freight wagons (excluding pneumatic components) consists of a brake cylinder, a slack adjuster, a system of levers, brake shoe holders, brake shoes and other components. Figure 2 depicts the classic braking system.

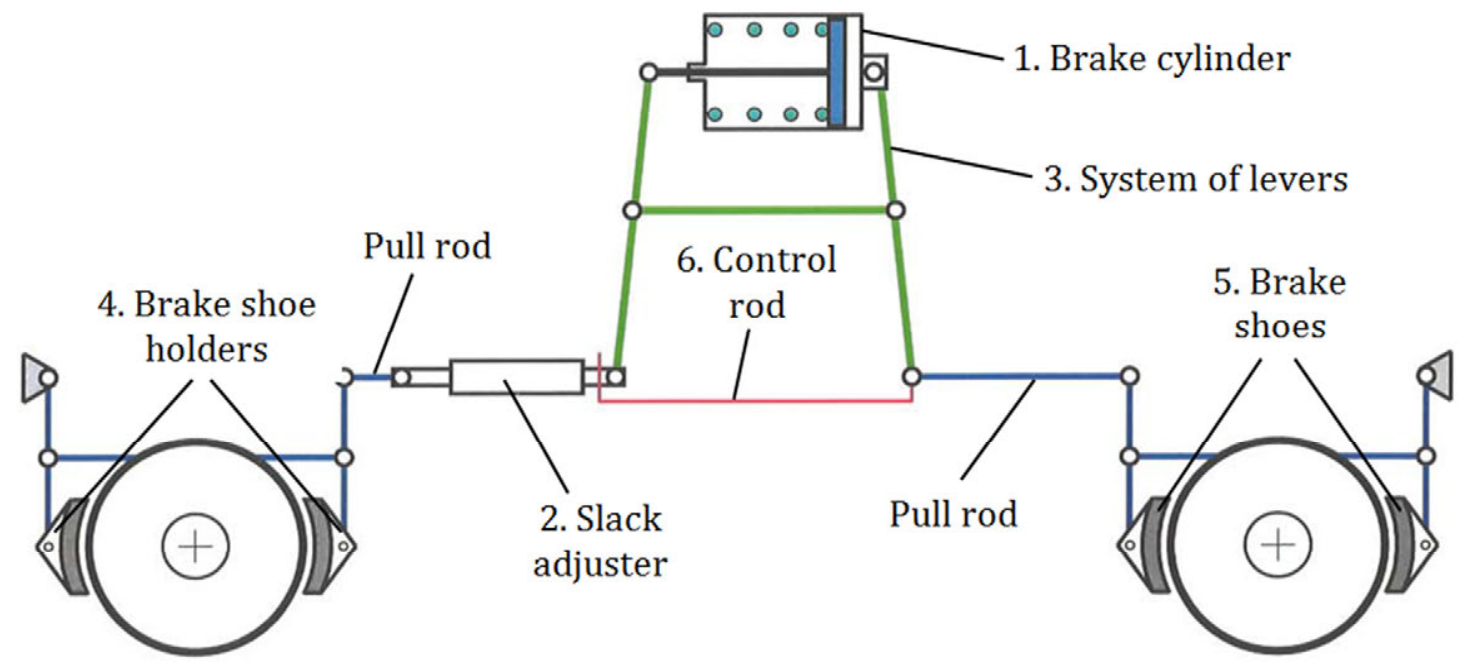

Fig. 2 Schematic diagram of the classic braking system [5]

The braking system is activated by the brake cylinder (1) from which the brake force is amplified and transferred by the system of levers(3) to the slack adjuster (2) and pull rods. From here, the force is transmitted to the brake shoe holders (4), onto the brake shoes (5) and applied to the wheels. The slack adjuster (2) serves to compensate for the wear of brake shoes (5) and wheels. The gap between the wheels and the brake shoes is adjusted by the operation of the brake cylinder (1). Where there is some wear of shoes or wheels, the stroke of the brake 
cylinder (1) will be larger than the nominal stroke, because it should compensate for the wear from the worn shoes or wheels. In this case, adjusting, i.e. compensation for the shoe or wheel wear, is performed by the control rod (6). In the next braking (if there is no additional wear of shoes or wheels), the brake cylinder (1) will have the nominal stroke. To adjust the gap between the wheels and the brake shoes, there is an option to adjust the length of the control rod (6).

Until the introduction of compact integrated braking systems, the simple design of the classic braking system made this system dominant in the market of rail freight vehicles around the world.

\subsection{Model of innovative braking system IBB 10}

As rail operators focus on the need for greater efficiency and safety improvements, there is a significant need for improvements of braking systems [5]. Advanced braking systems contribute to a number of benefits through an additional increase in the capacity of transported goods, increased safety and optimized life cycle costs [6].

The innovative braking system IBB 10 (Integrated Bogie Brake) of the brake manufacturer Wabtec MZT is designed for use in rail freight transport. One of the authors of this paper was a member of the team designing this innovative product. The model of this braking system consists of a brake cylinder that transfers the force on the brake shoe holders and on the brake shoes that come in frictional contact with the wheels of the wagon through a system of levers and slack adjusters. The key advantage of this braking system in comparison with the classic braking system is its lightweight design, high efficiency and equal brake force on all four wheels of the bogie. The brake force is achieved by the brake cylinder and multiplied by the levers. Two slack adjusters serve to compensate for the wear of the brake shoes and wheels. This braking system design allows easy assembly and disassembly on each sub-assembly separately, which is a great advantage for maintenance and repair of the system. The innovative IBB 10 braking system can be fitted between the wheels of a bogie type Y25 and it fits the standard built-in measures of the conventional braking system. The function of the innovative braking system is to provide an approximately equal brake force on all four wheels at the same time. The design is characterized by the use of a brake cylinder with (or without) a hand brake and two slack adjusters for automatic adjustment of the gap between the wheels and the brake shoes.

Figure 3 shows the innovative system IBB 10 without a handbrake. This model of the innovative IBB 10 system is a base for all other variants.

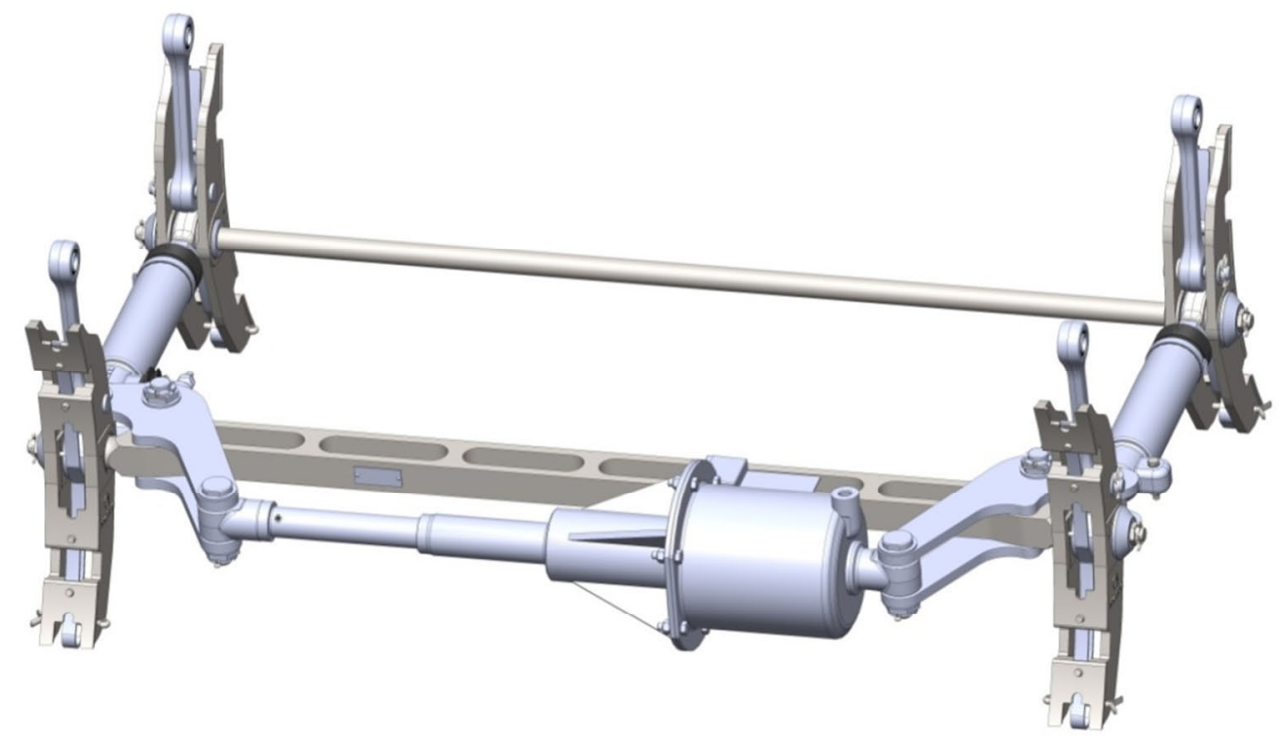

Fig. 3 The innovative IBB 10 model without a handbrake 
IBB 10 makes managing wagons more economical and more efficient. Thanks to its modular design, the IBB 10 is lightweight, easy to install and cost-effective. It offers low maintenance and low air consumption, while it is very efficient and life cycle costs are low.

This leads to an increased performance, which provides benefits to vehicle manufacturers and operators. The main advantages of IBB 10 are the following:

- modular construction (block force can be adjusted by changing the lever ratio without changing the installation space or the interface with the bogie and reduce installation time);

- low noise;

- low air consumption;

- it can be equipped with a handbrake mounted on the bogie and the brake cylinder;

- low weight (4-axle weight of the wagon is reduced by approximately $800 \mathrm{~kg}$ );

- high efficiency (brake efficiency is about 0.95, it does not change between two maintenance checks and it is independent of the pressure of the brake cylinder);

- low maintenance (there is no maintenance required between audits).

The functionality of the innovative IBB 10 braking system without a handbrake is to allow the application of the service brake force. The operating brake force is calculated using the following equation (1) [7]:

$$
F=\left(p \cdot S \cdot 10-F_{B}\right) \cdot i \cdot \eta-F_{S}(\mathrm{~N})
$$

In the equation, $p$ is the brake cylinder pressure (bar); $S$ is the effective piston area $\left(\mathrm{cm}^{2}\right) ; F_{B}$ is the return force from the brake cylinder spring $(\mathrm{N}) ; i$ is the lever ratio; $\eta$ is the efficiency and $F_{S}$ is the slack adjuster counterforce $(\mathrm{N})$.

From all the listed factors that influence the service brake force, only the brake cylinder pressure is a variable, while all the other factors are a constant [8]. Taking into account the fact that different types of freight wagons require a different brake force and the value of the pressure $p$ is defined according to the UIC standard, from a design point of view the ratio of the levers $i$ can be changed.

The innovative braking system IBB 10 is installed on one bogie, since one freight wagon usually has two bogies; in most cases two IBB 10 systems will be installed per wagon as a set. Because each freight wagon should have a parking option when removed from the train composition (or for some other reason), at least one IBB 10 unit must have a parking handbrake. Figure 4 shows a variant of the innovative braking system IBB 10 with a platform handbrake. This braking system with a platform handbrake has the same function as an IBB 10 without a handbrake, but with an added feature of the hand application of the parking brake. The platform handbrake is applied from the platform of the wagon. 


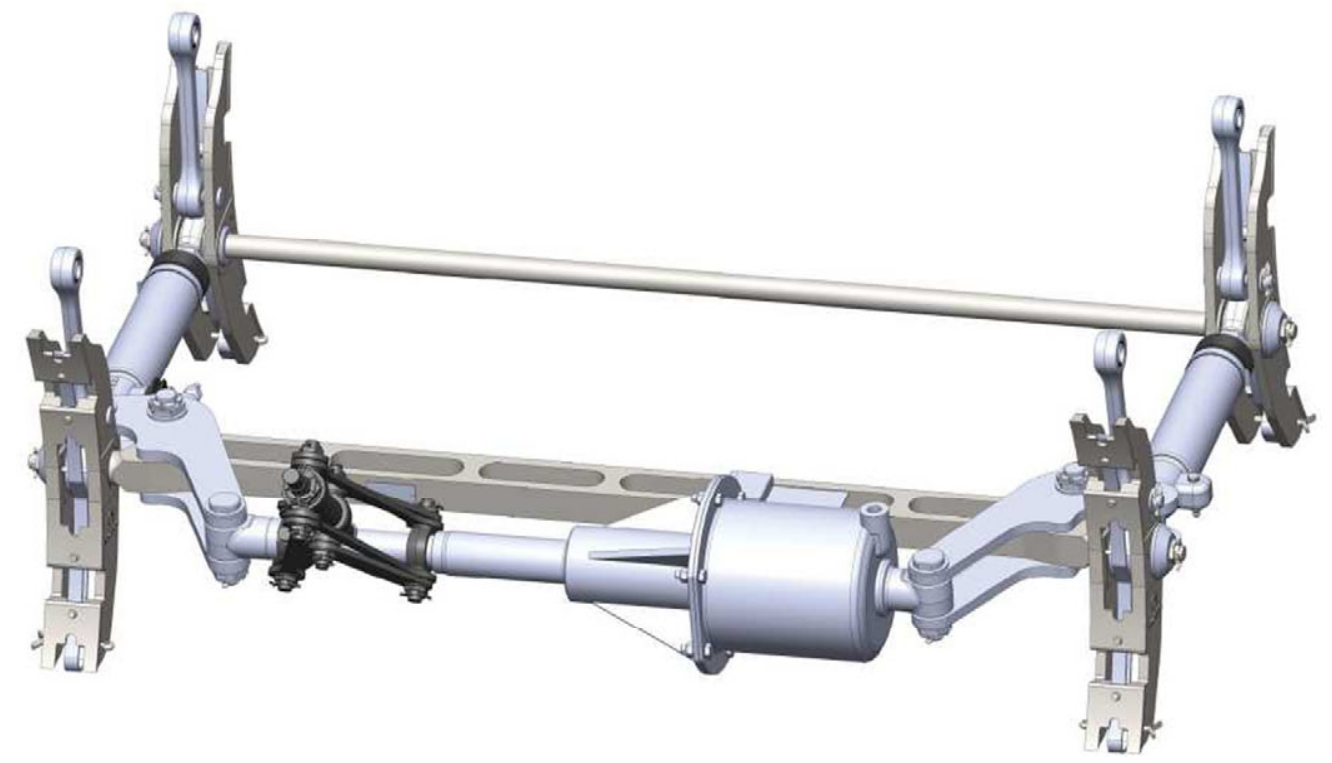

Fig. 4 The innovative IBB 10 model with a platform handbrake

The activation of the platform handbrake should be performed from the platform of the freight wagon by turning the hand wheel through a gearbox and a telescopic cardan shaft that is connected to the spindle of the platform handbrake mechanism. Figure 5 represents a model of a Y25 bogie with an installed IBB 10 braking system with a platform handbrake and connection components for activation with a segment of the wagon platform.

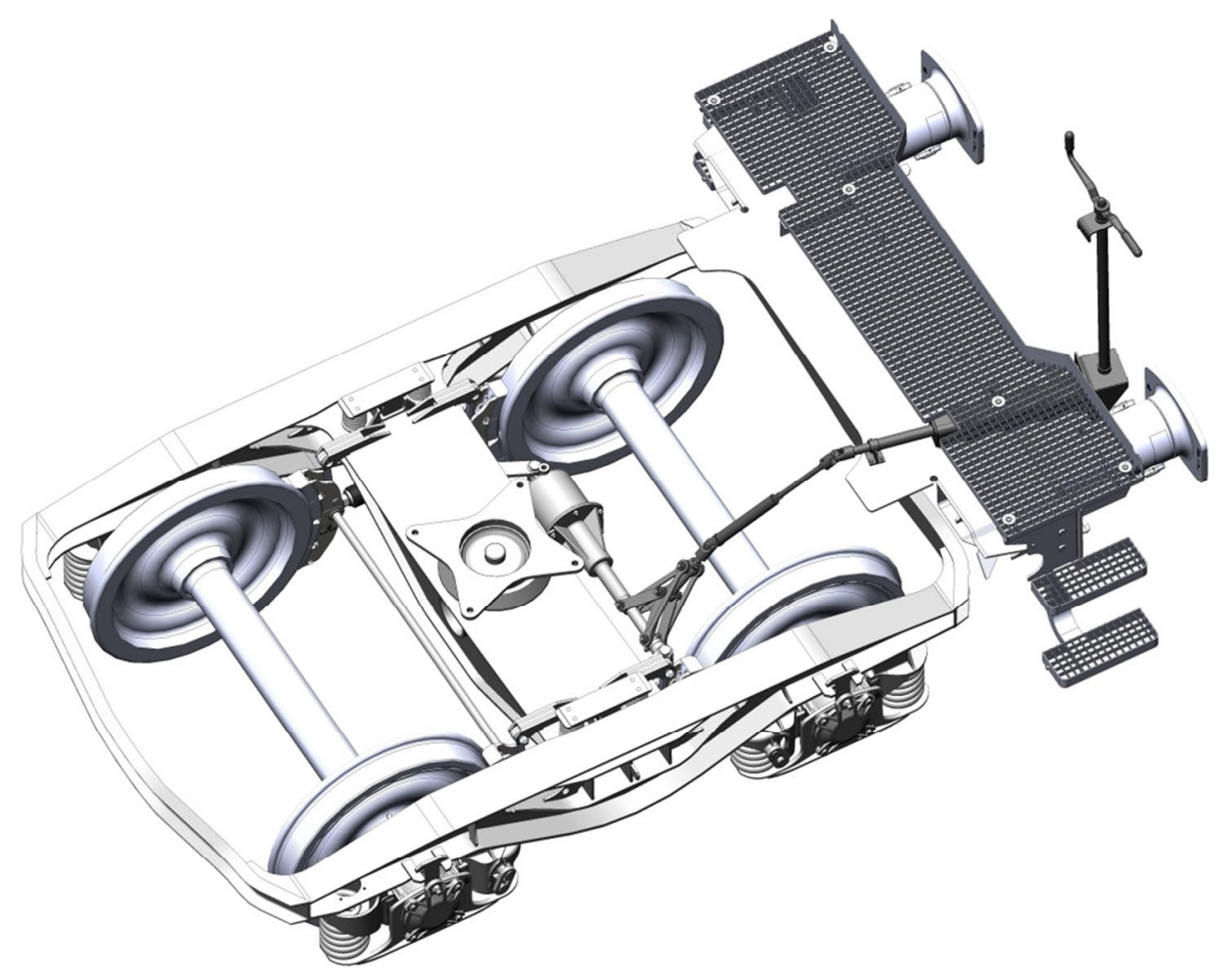

Fig. 5 Y25 stand with innovative IBB 10 system with manual platform brakes and connection elements for activation with a part of the wagon platform 


\section{Static testing}

Throughout the process of designing and developing new products, in order to be able to adopt the product and launch a serial production, it is necessary to check and validate the product first. Throughout the verification and validation process, several types of tests are carried out, depending on the needs and the definitions in the relevant standards. In this paper, we have focused only on the static testing and the slip testing.

Static testing is the first type of test that was performed to verify the functionality of a product [9]. This test should follow immediately after the prototype is assembled. The static testing process should be timely planned because it is necessary to have appropriate assembly tools for proper testing and, more importantly, to have a specialized test bench that will examine the functionality of the braking system.

The IBB 10 test design demonstrates all the functionalities in accordance with the defined UIC 541-01 criteria [11]. The test results are given in the table below to indicate that the product meets the required functionality. Table 1 shows the results of the static testing of the innovative braking system IBB 10 on a test bench. As you can see from the results, the braking system meets the required functionality.

Table 1 Static test results forbraking system IBB 10 on a static test bench

\begin{tabular}{|c|c|c|c|c|c|}
\hline No. & Type of test & Criteria & \multicolumn{2}{|c|}{ Results } & Activity \\
\hline 1 & $\begin{array}{c}\text { Installation } \\
\text { measures }\end{array}$ & $\begin{array}{c}\text { They must fit } \\
\text { with the } \\
\text { interfacedrawing }\end{array}$ & \multicolumn{2}{|c|}{$\begin{array}{l}\text { OK, fits the } \\
\text { installation } \\
\text { dimensions } \\
\text { according to the } \\
\text { interface drawing }\end{array}$} & $\begin{array}{l}\text { Compare whether } \\
\text { the above } \\
\text { installation } \\
\text { measures } \\
\text { correspond with } \\
\text { the installation } \\
\text { dimensions of the } \\
\text { drawing }\end{array}$ \\
\hline \multirow[t]{2}{*}{2} & \multirow{2}{*}{$\begin{array}{l}\text { Slack adjuster } \\
\text { capacity }\end{array}$} & \multirow[t]{2}{*}{$R=200_{0}^{+10} \mathrm{~mm}$} & Left side & Right side & Measure min. and \\
\hline & & & $\mathrm{OK}$ & $\mathrm{OK}$ & $\begin{array}{l}\text { adjuster length. } \\
\text { The difference } \\
\text { between max. and } \\
\text { min. length is the } \\
\text { capacity }\end{array}$ \\
\hline 3 & $\begin{array}{l}\text { Gap between } \\
\text { braking wheels } \\
\text { and shoes }\end{array}$ & $\begin{array}{c}\text { Total } 14_{0}^{+4}(\mathrm{~mm}) \\
\text { per side }\end{array}$ & 16.1 & 15.5 & $\begin{array}{l}\text { Measure the gap } \\
\text { on the left and } \\
\text { right side }\end{array}$ \\
\hline 4 & Brake force & $\begin{array}{c}F=30.0 \pm 7 \% \\
\mathrm{kN}\end{array}$ & \multicolumn{2}{|c|}{$\begin{array}{l}F_{\mathrm{A}}=28.9 \mathrm{kN} \\
F_{\mathrm{B}}=29.2 \mathrm{kN} \\
F_{\mathrm{C}}=28.5 \mathrm{kN} \\
F_{\mathrm{D}}=29.4 \mathrm{kN}\end{array}$} & $\begin{array}{l}\text { Apply pressure of } \\
\text { 3.8bar to the } \\
\text { brake cylinders } \\
\text { and measure the } \\
\text { brake forces at } 4 \\
\text { measuring points }\end{array}$ \\
\hline
\end{tabular}


The static testing of the innovative braking system IBB 10 has measured and validated the following characteristics:

- geometry;

- kinematics;

- static strength at room temperature;

- $\quad$ static efficiency at room temperature;

- functionality at room temperature.

\section{Slip testing}

In order to show the benefits of the innovative braking system IBB 10, the slip testing results will be compared with the slip testing results of the classic braking system [10]. The slip test was conducted on Falns wagons. Tables 2 and 3 show the pressures and the brake forces of the classic brake and of IBB 10.

The Falns wagon on which these braking systems were installed had the following characteristics:

- weight of an empty wagon: $20,500 \mathrm{~kg}$

- gross vehicle weight: $90,000 \mathrm{~kg}$

- number of axles per wagon: 4

- bogie type: Y25

- nominal axle base: $1,800 \mathrm{~mm}$

- maximum speed: $100 \mathrm{~km} / \mathrm{h}$

Table 2 Brake cylinder pressure

\begin{tabular}{|c|c|c|c|c|}
\hline \multicolumn{3}{|c|}{ FALNS wagon } & Classic brake & IBB 10 \\
\hline \multirow{2}{*}{ Brake cylinder } & \multirow{2}{*}{ bar } & Empty wagon & 1.36 & 1.10 \\
\cline { 3 - 5 } & & Loaded wagon & 3.80 & 3.75 \\
\hline
\end{tabular}

Table 3 Brake shoe force

\begin{tabular}{|c|c|c|c|c|}
\hline \multicolumn{3}{|c|}{ FALNS wagon } & Classic brake & IBB 10 \\
\hline \multirow{2}{*}{ Brake force } & \multirow{2}{*}{$\mathrm{kN}$} & Empty wagon & 8.36 & 7.35 \\
\cline { 3 - 5 } & & Loaded wagon & 29.40 & 29.00 \\
\hline
\end{tabular}

Both wagon brakes have an automatic brake force change in relation to the weight of the wagon and are equipped with composite K-type brake shoes. The wagon with the IBB 10 system had the maximum brake cylinder pressure adjusted to 3.6 bar from 3.8 bar, which is regularly used with standard cargo brakes. Lower pressure causes less wear on the brake shoes. Based on the calculation, the following parameters of the braking system were selected (see Table 2 and Table 3). 
4.1 Analysis of the brake weight results for the classic braking system and IBB 10 installed in a Falns wagon

The braking performance of the railway vehicles can be expressed by the brake weight. Brake weight is the basic braking parameter expressed in the number of tons. The weight of the brakes of these wagons was determined on the basis of the slip test in accordance with UIC 544-1. The first test results did not meet the minimum brake performance from the CR TSI VAG 2013, Table C.3 for a wagon fitted with a variable relay valve. At a nominal cylinder pressure of 1.36 bar, the following results were obtained:

$$
\begin{aligned}
& S_{\text {corr }}=395 \mathrm{~m}, \lambda=135 \% \text { for } 100 \frac{\mathrm{km}}{\mathrm{h}} \text { and } \\
& S_{\text {corr }}=500 \mathrm{~m}, \lambda=140 \% \text { for } 120 \frac{\mathrm{km}}{\mathrm{h}} .
\end{aligned}
$$

In the equation, $S_{\text {corr }}$ is the corrected braking distance and $\lambda$ is the percentage of the brake weight.

Also, with a nominal cylinder pressure of 3.8 bar in the partially loaded $M=59.7 \mathrm{t}$, the first two tests gave the following results:

$$
\begin{aligned}
& S_{\text {corr }}=405 \mathrm{~m}, \lambda=120,5 \% \text { for } 100 \frac{\mathrm{km}}{\mathrm{h}} \text { and } \\
& S_{\text {corr }}=575 \mathrm{~m}, \lambda=126,5 \% \text { for } 120 \frac{\mathrm{km}}{\mathrm{h}} .
\end{aligned}
$$

The measured percentages of brakes were above the values permitted by EN 14198. The pressure of the brake cylinder was reduced by using a relay valve at 1.2 bar in the case of an empty wagon and 3.4 bar in the case of a freight wagon.

With the new brake cylinder pressure values, a slip test was performed and the following results were obtained (see Table 4) where: $M$ is the weight of the wagon; $V$ is the initial speed; $S_{\text {corr }}$ is the corrected stopping path; $\lambda$ is the percentage of the weight of the brake; $B$ is the weight of the brake and $B_{U I C}$ is the rounded weight of the brake that will be marked on the wagon.

Table 4 Brake weight - classic brake

\begin{tabular}{|c|c|c|c|c|c|c|}
\hline $\begin{array}{c}\text { Braking } \\
\text { mode }\end{array}$ & $M$ & $V$ & $S_{\text {corr }}$ & $\lambda$ & $B$ & $B_{\text {UIC }}$ \\
\hline \multirow{4}{*}{$\mathrm{P}$} & $\mathrm{t}$ & $\mathrm{km} / \mathrm{h}$ & $\mathrm{m}$ & $\%$ & $\mathrm{t}$ & $\mathrm{t}$ \\
\cline { 2 - 7 } & \multirow{2}{*}{20.8} & 100 & 432.1 & 112.3 & 23.4 & 23 \\
\cline { 2 - 7 } & \multirow{2}{*}{59.70} & 120 & 616.8 & 116.6 & 24.3 & 24 \\
\cline { 2 - 7 } & & 100 & 491.6 & 97.5 & 58.2 & 58 \\
\cline { 2 - 7 } & 89.85 & 120 & 682.3 & 103.6 & 61.8 & 62 \\
\hline
\end{tabular}

Table 5 presents the results of the test for a wagon equipped with the innovative braking system IBB 10. 
Table 5 Brake weight- IBB 10

\begin{tabular}{|c|c|c|c|c|c|c|}
\hline $\begin{array}{c}\text { Braking } \\
\text { mode }\end{array}$ & $M$ & $V$ & $S_{\text {corr }}$ & $\lambda$ & $B$ & $B_{\text {UIC }}$ \\
\hline \multirow{3}{*}{$\mathrm{P}$} & $\mathrm{t}$ & $\mathrm{km} / \mathrm{h}$ & $\mathrm{m}$ & $\%$ & $\mathrm{t}$ & $\mathrm{t}$ \\
\cline { 2 - 7 } & \multirow{2}{*}{20.8} & 100 & 474.6 & 101.3 & 21.1 & 21 \\
\cline { 2 - 7 } & \multirow{2}{*}{59.8} & 120 & 650.3 & 109.6 & 22.8 & 23 \\
\cline { 2 - 7 } & & 100 & 476.1 & 101.0 & 60.4 & 60 \\
\cline { 2 - 7 } & 90.05 & 100 & 668.4 & 106.1 & 63.5 & 63 \\
\hline
\end{tabular}

Graphs shown in Figures 6 and 7 illustrate the two recorded tests. The following tags are used in the graph; $p_{B P}$ is the pressure in the brake pipe; $p_{B C}$ is the pressure in the brake cylinder; $V$ is the speed and $\mathrm{s}$ is the distance travelled.

The stopping distance is derived from the distance travel data for each individual test as a path that passes between the starting torque of the drop in the main brake line until the speed reaches zero.

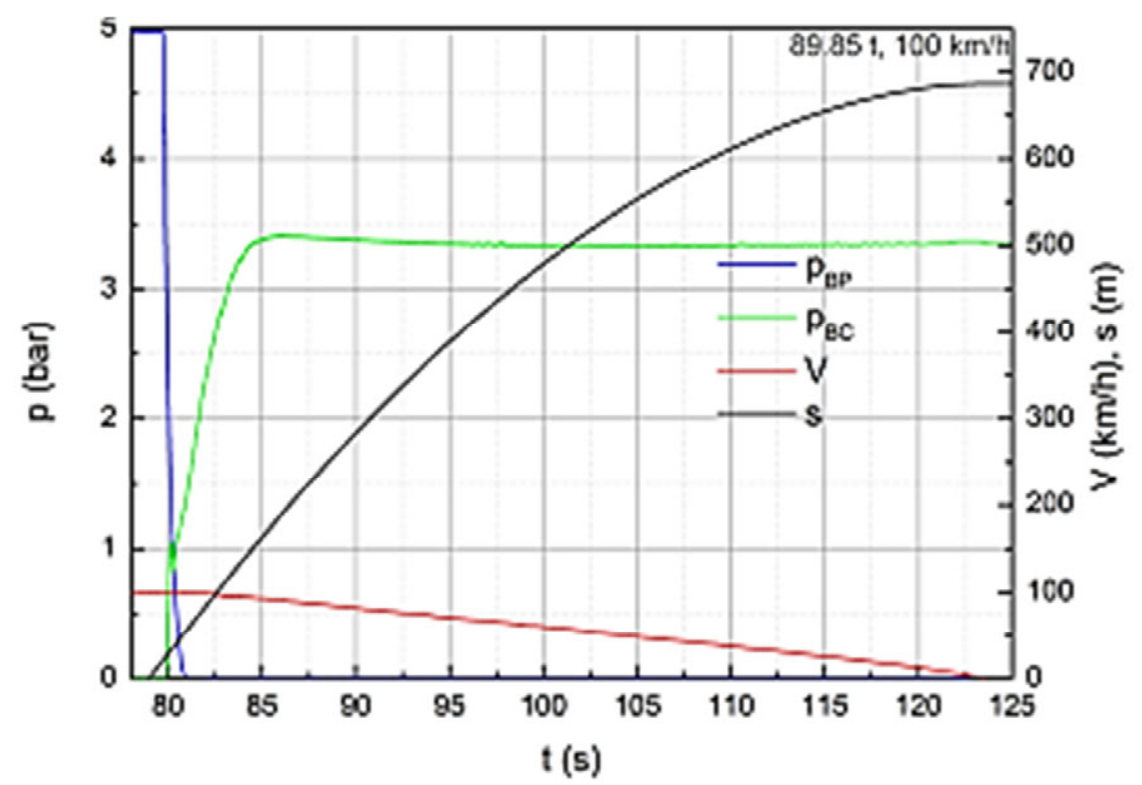

Fig. 6 Slip test, wagon with classic brakes 


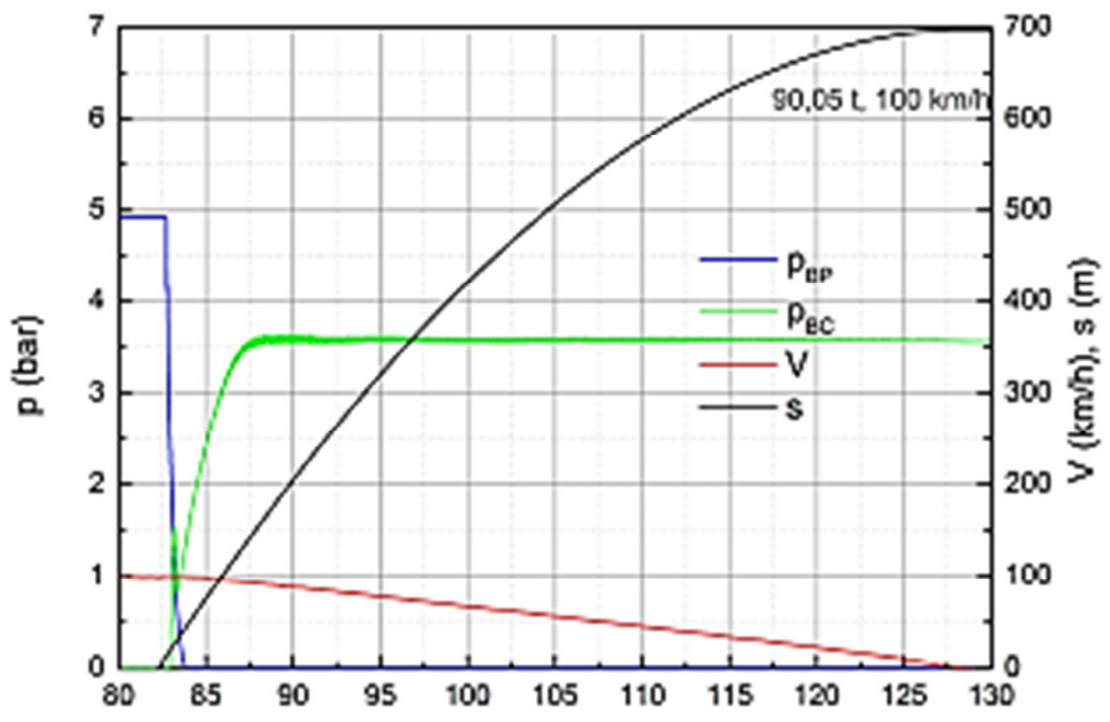

Fig. 7 Slip test, wagon with IBB 10

Since the results of all the tests on the innovative IBB 10 braking system are positive, it can be concluded that the product has successfully passed the tests.

\section{Conclusion}

This paper presents a validation test of a complex mechanical unit, i.e. an innovative braking system for freight wagons. Since the braking system is of great importance for the safety of rail traffic and is exposed to high static and dynamic loads, a number of tests are required to validate it. Static and slip tests are among the tests that are used to validate the braking system. Static test is one of the first indicators that shows whether the braking system functions correctly, while the slip test is one of the final validation tests. In order to increase the chances of the product to pass validation tests, it is very important to use the most advanced software, methods and techniques during the design process. The results from the performed tests are positive, which means that the innovative braking system IBB 10 has successfully completed the validation tests and that the braking system satisfies the UIC standard criteria and meets customers' requirements. The successful completion of the validation tests increases significantly the chance of the innovative braking system to be successfully marketed.

\section{REFERENCES}

[1] References should be formatted using REF Body style to look as presented. Long references will spread across lines. Bhuiyan N., 2011, A framework for successful new product development, Journal of Industrial Engineering and Management (JIEM), Volume 4, Issue 4, pp. 746-770.

[2] Dukovski, V., 2001, Менацментнаразвојотнановипроиводи (Management of New Product Development), Ss. Cyril and Methodius University, Skopje.

[3] Lunden R., Vernersson T., 2016, Mechanical braking systems - development and challenges, Presentation at 19th Nordic Seminar on Railway Technology, Chalmers University of Technology, Lulea, September 14-15.

[4] http://www.railway-technical.com/trains/rolling-stock-index-1/train-equipment/brakes/

[5] Smileski T., Rakipovski R., Mičić M., 2016, Comparison of Classical Brake for Freight Wagons with New Integrated Bogie Brake IBB 10 for Freight Wagons, RAILKON `16, Niš, October 13-14.

[6] Wynd D., Connelly M., 2010, Advanced Bogie Brakes, Proceedings, Conference on Railway Engineering, Wellington, September 12-15. 
[7] Smileski T., 2017, Integrated bogie type IBB 10, Interface drawing K - 329.721/14, Wabtec MZT.

[8] Weidemann C., 2010, State of the Art Railway Vehicle Design with Multi-Body Simulation, Journal of Mechanical Systems for Transportation and Logistics, Vol. 3, No 1, pp. 12-26.

[9] BS EN 13749:2011, 2011, Railway Applications - Wheelsets and bogies. Method of specifying the structural requirements of bogie frames.

[10] Artner W., 2013, MBD/FEA-Analysis IBB 10 Brake System New Design, Report a 13010 RV0, November.

[11] UIC 541-01, 2017, Brakes - Brake cylinders/units for air brakes - General conditions for certification and use, $1^{\text {st }}$ edition, March.

$\begin{array}{lll}\text { Submitted: } & 21.9 .2019 & \text { Erdinč Rakipovski } \\ & & \text { Dragan Milčič } \\ \text { Accepted: } & 06.5 .2020 & \text { Faculty of Mechanical Engineering } \\ & & \text { University of Niš, Niš, Serbia }\end{array}$

